\title{
Evaluate the Effect of Using Source of Nitrogen (Soaked Brown Lentils) on Chemical Composition for Marine Microalgae Nannochlorpsis oceanica
}

\author{
Ali M. Abugrara \\ Marine Resources Department, Faculty of Natural Resources and Environmental Sciences \\ Omar Al-Mokhtar University, El-Beda, Libya. \\ E-mail: amhofm1963@gmail.com
}

Received: June 1, 2021 Accepted: July 21, $2021 \quad$ Published: September 8, 2021

doi:10.52941/ast.v10i1.19 URL: https://doi.org/10.52941/ast.v10i1.19

\begin{abstract}
Microalgae culture media must be efficient, give high growth, meet micro-requirement, and be available. The effect of different levels of brown lentil infusion and use at [25, 50 and 75\%] levels on the chemical composition (protein, carbohydrates, fatty acids, and amino acids) in $N$. oceanic was evaluated. Compared to the standard F/2 Guillard. The obtained results indicated that the chemical components of $N$. oceanica were affected by these levels. The highest protein and carbohydrate content and the highest EAA content $(55.92 \%)$ were obtained using OB3 medium (75\% SBL) compared to the control group (100\% F/2). The highest biomass production was obtained in OB3 medium. The highest TSFA and USFA were recorded for $N$. oceanica by the OB3 mean.

The present study recommended that it is possible to use microalgae grown on OB3 and OB2 medium as a lipid and protein inducer in aquaculture.

Keywords: Amino acids, Fatty acids, Nannochloropsis oceanica, Proximate composition

\section{Introduction}

Microalgae are a large group of autotrophic eukaryotic organisms that play important roles in marine and freshwater ecosystems (Zhu y. Donford NT., 2013; Piggott et al., 2015). Microalgae with high growth rates in various cultural conditions, microalgae, exploit some chemical components in many fields, including biotechnology, food science, and aquaculture (Templeton
\end{abstract}


\& Lewins, 2015). Microalgae are a source of many important elements in biomedicine and balanced nutrients but also in technology. In addition to their natural use in aquaculture, microalgae are used directly in feed for larvae and young aquaculture (Sarker et al., 2016). Knowledge of other aspects is needed in order to increase aquaculture production to generate new, high-quality species of microalgae and use microalgae species as feed sources (Hemaiswarya et al., 2011). Microalgae help improve the traditional nutritional value of foods and promote the growth and development of various food products (Tokuşoglu \& nal, 2003).

The chemical composition of microalgae may vary with cultural conditions and age (Carvalho $e t$ al., 2009). Diverse cultures influence the types of microalgae that have been studied for the purpose of understanding and knowing their potential for use in aquaculture (Grobbelaar, 2010). Among the various nutritional factors, nitrogen is one of the most important nutrients for growth, as it is a component of all structural and functional proteins such as peptides, enzymes, chlorophyll, energy transport molecules and genetic material in algal cells (Cai et al., 2013). The concentration of nitrogen in the culture medium significantly affects both the cell growth rate and the biochemical compositions of microalgae (Wang et al., 2013), and several studies have shown that when nitrogen is limited in the culture medium, the cell growth rate of microalgae slows down and increases their fat or carbohydrate content, which reduces protein synthesis (Ho et al., 2014). Most microalgae are able to use different forms of nitrogen, including sources of nitrate, nitrite, ammonium, and organic nitrogen such as urea (Baker, 1994); Each nitrogen source is first converted to the ammonium form and assimilated into amino acids through a variety of pathways (Cai et al., 2013).

Demand is increasing for algal lipids which can be produced by biosynthesis of active lipids using appropriate nutrients as well as by improved harvesting strategies that lead to cell/biomass recovery.

Various physical and chemical conditions such as temperature, stress, light intensity, culture time, organic carbon and inorganic nutrients including iron $(\mathrm{Fe})$, phosphorous $(\mathrm{P})$, nitrogen $(\mathrm{N})$, manganese $(\mathrm{Mn})$, zinc $(\mathrm{Zn})$, sulfur $(\mathrm{S})$, cobalt $(\mathrm{Co})$, and others, influence the growth and lipid accumulation of many types of microalgae (Bajpai et al., 2014).

At the level of industrial production of marine hatcheries, the improvement of the efficient culture medium for microalgae species for food culture is absolutely necessary. The nutrient media for microalgae should be quick to prepare, less expensive, produce high growth, and meet the quality and quantity of microalgae in terms of chemical composition. Although F / 2 Guillard medium is the most common method of culturing Nanochloropsis in marine hatcheries, the F / 2 medium has some drawbacks, such as difficulties in preparation and may in some cases be costly.

This study was designed to evaluate the effects of adding different levels of brown lentil infusion on the biochemical composition of $N$. oceanica and the rate of production of fatty acids and amino acids. Therefore, different media were prepared using different levels to culture $N$. oceanica to replace F / 2 medium to reduce production cost. However, the question is whether $N$. 
oceanica cultured at different levels of brown lentil infusion could be effective.

\section{Materials and Methods}

\subsection{Microalgal Strains}

Nannochloropsis oceanica strain was from an algae unit of the marine hatchery at the kilo 21 Alexandria - Egypt.

N. oceanica were kept Institute of Oceanography and Fisheries (NIOF), Egypt and cultured under controlled conditions of temperature $\left(22 \pm 2 \mathrm{C}^{\circ}\right)$, salinity $(35 \pm 2 \mathrm{ppt})$.

F/2 medium (Guillard and Rhyter, 1962), with continuous ventilation and 8:16 h of light, was used in three replicates. Dry weight (CDW) and chemical composition of algal cells (10 days after culturing) were determined. And dry weight (CDW) was determined, according to (Abomohra, et al., 2013).

\subsection{Experimental Design}

The F/2 medium contained (mg. $\mathrm{L}^{-1}$ ) $\mathrm{NaNO}_{3}, 75 ; \mathrm{NaH}_{2} \mathrm{PO}_{4} \cdot \mathrm{H}_{2} \mathrm{O}, 5 ; \mathrm{Na}_{2}$ EDTA. $\mathrm{H}_{2} \mathrm{O}$, 4.16; $\mathrm{FeC1}_{3} .6 \mathrm{H}_{2} \mathrm{O}, 3.15 ; \mathrm{CuSO}_{4} .5 \mathrm{H}_{2} \mathrm{O}, 0.01 ; \mathrm{ZnSO}_{4} .7 \mathrm{H}_{2} \mathrm{O}, 0.022 ; \mathrm{COC1}_{2} .6 \mathrm{H}_{2} \mathrm{O}, 0.01 ; \mathrm{MnC1}_{2} .4 \mathrm{H}_{2} \mathrm{O}$, 0.18; $\mathrm{Na}_{2} \mathrm{MoO}_{4} .2 \mathrm{H}_{2} \mathrm{O}, 0.006$; Vitamin B12, 0.0005; Vitamin B1, 0.1; and Bi-tin, 0.0005 (Guillard \& Rhyter, 1962).

\subsection{Culture Conditions}

Use 1.5 liter plastic containers filled with 1 liter sterile saline $(35 \pm 2)$ and $4 \mathrm{gm}$

of brown lentils were soaked in $50 \mathrm{ml}$ of sterile water for 15 minutes. It was put on the stove for 5 minutes and left to cool. The solution was filtered with filter paper and used at levels as described in (Table 1).

\subsection{Estimation of the Biochemical Constituents of $N$. oceanica}

The total protein and carbohydrate content was estimated by (Lowry et al., 1951) using Bovine Serum Albumin (BSA) as a standard. (Dubois et al., 1956) and quantification of total carbohydrate "phenol-sulfuric acid" using d-glucose $\mu \mathrm{g} / \mathrm{ml}$ as a standard.

\section{Biomass productivity $\left(\mathrm{mg} \mathrm{L}^{-1}\right.$ day $\left.^{-1}\right)=\left(\mathrm{CDW}_{\mathrm{L}}-\mathrm{CDW}_{\mathrm{E}}\right) \times\left(\mathrm{t}_{\mathrm{L}}-\mathrm{t}_{\mathrm{E}}\right)^{-1}$.}

With $\mathrm{CDW}_{\mathrm{E}}$ representing the $\mathrm{CDW}\left(\mathrm{mg} \mathrm{L}^{-1}\right)$ at the days of early exponential phase $\left(\mathrm{t}_{\mathrm{E}}\right)$ and $\mathrm{CDW}_{\mathrm{L}}$ at the days of late exponential phase $\left(\mathrm{t}_{\mathrm{L}}\right)$. (Abomohra , et al., 2016).

\subsection{Total Lipid Content and Fatty Acids Profile}

Total lipids and fatty acids were extracted as described by (Folch et al. 1957) and (Bligh \& Dyer, 1959). The fatty acids were determined using methyl ester from total fat according to a procedure (Radwan, 1978). 
All analyzes for fatty acid determination were performed on a GS-MS instrument, an HP (Hewlett Packard) 7890 GC equipped with a flame ionization detector. GC terms: Device model: HP (Hewlett Packard) 6890GC, Shaft: HP-INNOWax (polyethylene glycol), 60 m, ID 0.25 mm, film thickness of $0.2 \mu \mathrm{m}$. Detector: FID (Flame Ionization Detector). Detector temperature: $250^{\circ} \mathrm{C}$. Injector temperature: $220^{\circ} \mathrm{C}$, injection volume $3 \mu \mathrm{l}$, split ratio 50:1.

\subsection{Amino Acids Determination}

Amino acids of $N$. oceanica were analyzed by hydrolysis in $6 \mathrm{~N} \mathrm{HCL}$ for $22 \mathrm{hrs}$ at $110^{\circ} \mathrm{C}$; after hydrolysis, the acid was evaporated in a vacuum oven. The residue of the algal sample was dissolved in $1 \mathrm{ml}$ of sample dilution (diluting buffer) $(0.2 \mathrm{M}, \mathrm{pH} 2.2)$ to complete the sample dissolving. Automatic amino acid analyzer was used for amino acid determination (Dionex ICS3000) (Block, 1948).

\subsection{Statistical Analysis}

Statistical analysis was performed using analysis of the one way (ANOVA) was used to test the effects of urea on chemical composition of microalgae. Duncan.

One- way ANOVA was used to match the mean differences by the Statistical Package for the Social Sciences SPSS (2007). As such, the differences were small to be significant at $\mathrm{p}<0.05$.

Table 1. Design of the experiment used to grow Nannochloropsis oceanica

\begin{tabular}{|c|c|c|c|c|}
\hline & Control (CO) & OB1 & OB2 & OB3 \\
\hline F/2 & 100 & -- & -- & - \\
\hline F/2 & -- & 0.75 & 0.50 & 0.25 \\
\hline Soaked Brown Lentils (SBL) & --- & 0.25 & 0.50 & 0.75 \\
\hline
\end{tabular}

\section{Results}

Nannochloropsis oceanica was cultured at different concentrations as shown in Table (1) in the early stationary stage, from which samples were harvested for chemical composition analysis after the late stationary stage (10 days). Cell dry weight and chemical composition were examined. The presented results indicated that there was no significant difference in dry weight (CDW) between the media containing different levels of mixture and control.

Table (2) showed significant differences in the chemical composition of algae between the different levels. The highest percentages of protein and carbohydrates for dry weight $(22.79 \% \pm$ 0.03 and $21.82 \% \pm 0.03$, respectively) were shown by OB3 medium (75\% SBL and 25\% F/2) compared to control and other treatments. The highest total fat content $(37.64 \% \pm 0.03)$ was shown by the mean $\mathrm{F} / 2$ relative to the other treatments. 


\subsection{Biomass Productivity}

The data obtained in Table (2) showed significant differences in the biomass productivity of $N$. oceanica species between the different treatments. The highest percentage of dry weight (121.47 \pm 0.03 and $109.49 \pm 0.02$ (mg L-1 day-1, respectively) was obtained by medium OB3 (75\% SBL and $25 \% \mathrm{~F} / 2)$ and medium $\mathrm{OB} 2(50 \% \mathrm{SBL})$. and 50\% F/2 when compared to the control group and other treatments.

Table 2. Chemical composition (percent based on dry weight) $\mathrm{mg} / \mathrm{g}$ dry weight of $N$. oceanica at different levels of soaked brown lentil (SBL) medium harvested after 10 days of incubation.

\begin{tabular}{|c|c|c|c|c|c|}
\hline Medium & $\begin{array}{l}\text { CDW } \\
\left(\mathrm{g} \mathrm{L}^{-1}\right)\end{array}$ & $\begin{array}{c}\text { Protein } \\
(\% \mathrm{CDW})\end{array}$ & $\begin{array}{c}\text { Carbohydrate } \\
\text { (\% CDW })\end{array}$ & Lipid (\% CDW) & $\begin{array}{c}\text { Biomass productivity } \\
\quad\left(\mathrm{mg} \mathrm{L}^{-1} \text { day }^{-1}\right)\end{array}$ \\
\hline $\mathrm{CO}$ & $0.82 \pm 00^{b}$ & $19.46 \pm 0.02^{\mathrm{d}}$ & $18.36 \pm 0.02^{\mathrm{c}}$ & $37.64 \pm 0.03^{\mathrm{a}}$ & $94.87 \pm 0.02^{\mathrm{d}}$ \\
\hline OB1 & $0.82 \pm 00^{\mathrm{bb}}$ & $19.76 \pm 0.02^{\mathrm{c}}$ & $19.84 \pm 0.02^{\mathrm{d}}$ & $36.72 \pm 0.03^{b}$ & $105.28 \pm 0.02^{c}$ \\
\hline OB2 & $0.83 \pm 00^{\mathrm{a}}$ & $21.54 \pm 0.02^{b}$ & $20.63 \pm 0.02^{b}$ & $36.44 \pm 0.02^{c}$ & $109.49 \pm 0.02^{b}$ \\
\hline OB3 & $0.83 \pm 00^{\text {aa }}$ & $22.79 \pm 0.03^{\mathrm{a}}$ & $21.82 \pm 0.03^{\mathrm{a}}$ & $34.72 \pm 0.03 \mathrm{~d}$ & $121.47 \pm 0.03^{\mathrm{a}}$ \\
\hline
\end{tabular}

Data are statistically analyzed using ONE-WAY ANOVA. Significant result is obtained at $\mathrm{P}=0.05$

\subsection{The Fatty Acids Analysis}

The fatty acid profile of $N$. oceanica was presented in Table 3. The data showed that there was no change in the fatty acid profile between the different milieus. In contrast, there is a noticeable change in the content of each individual fatty acid between the different media. The most abundant saturated fatty acid was palmitic acid (C16:0), which scored the highest value (27.62\%) in MF3 medium compared to other media. Palmitic acid is followed by myristic acid (C14:0).

In addition, oleic acid (C18:1) was the most prevalent monounsaturated fatty acid in all treatments, as it scored the highest values and was (25.46\%) with OB3 medium, which means that the oleic acid content increased with the increase in lentil soaked medium. Palmitoleic acid (C16:1) also showed an increase of (24.21\%) in mean OB2. Moreover, linoleic acid (C18:2) was the most common polyunsaturated fatty acid in all treatments, as the data showed that the highest value of this fatty acid (16.45\%) was recorded using OB3 medium, and eicosapentaenoic acid (EPA) was the second is polyunsaturated fatty acids, which recorded the highest percentage $(4.33 \%)$ in the OB3 medium. Similarly, docosahexaenoic acid (DHA) was the third polyunsaturated fatty acid that scored the highest value $(12.83 \%)$ with the mean OB3.

The results revealed that the highest percentage of total saturated fatty acids TSFA $(38.81 \%)$ was obtained by $\mathrm{OB} 2$ medium. The present study explained that the highest rate of the total unsaturated fatty acids USFA $(68.61 \%)$ was detected by OB3 medium, where this percentage is mainly consisting of $34.79 \%$ MUFA and $33.82 \%$ PUFA. On the other hand, the highest ratio (0.66) between SFA/USFA was achieved by CO. In addition, the highest ratios between $n-3 / n-6$ were $1.12 \%$ which exhibited by $\mathrm{CO}$ medium and DHA/EPA were 2.50 obtained by OB3 medium 
(Table 3).

Table 3. Shows the fatty acid percentages (\%) of $N$. oceanica at different levels of medium and the harvest was 10 days after incubation period Soaked brown lentil (SBL)

\begin{tabular}{|c|c|c|c|c|}
\hline Fatty acid & $\mathrm{CO}$ & OB1 & OB2 & OB3 \\
\hline C14:0 ( Myristic acid) & $3.51 \pm 0.02^{\mathrm{d}}$ & $5.12 \pm 0.01^{\mathrm{c}}$ & $5.24 \pm 0.02^{\mathrm{a}}$ & $5.15 \pm 0.02^{b}$ \\
\hline C15:0 (Pentadecylic acid ) & $0.54 \pm 0.02^{\mathrm{d}}$ & $0.82 \pm 0.01^{\mathrm{a}}$ & $0.79 \pm 0.02^{\mathrm{b}}$ & $0.76 \pm 0.01^{\mathrm{c}}$ \\
\hline C16:0 ( Palmitic acid ) & $20.27 \pm 0.02^{\mathrm{d}}$ & $23.16 \pm 0.02^{c}$ & $24.21 \pm 0.02^{\mathrm{b}}$ & $23.32 \pm 0.02^{\mathrm{a}}$ \\
\hline C17:0 ( Margaric acid) & $0.29 \pm 0.02^{\mathrm{d}}$ & $0.72 \pm 0.01^{\mathrm{a}}$ & $0.67 \pm 0.02^{\mathrm{c}}$ & $0.69 \pm 0.02^{b}$ \\
\hline C18:0 ( Stearic acid ) & $3.64 \pm 0.02^{\mathrm{d}}$ & $4.77 \pm 0.02^{\mathrm{b}}$ & $4.94 \pm 0.02^{\mathrm{a}}$ & $4.69 \pm 0.02^{\mathrm{c}}$ \\
\hline C21:0 ( Heneicosanoic acid ) & $0.68 \pm 0.02^{\mathrm{c}}$ & $1.11 \pm 0.02^{\mathrm{a}}$ & $1.09 \pm 0.02^{\mathrm{b}}$ & $1.09 \pm 0.01^{\mathrm{bb}}$ \\
\hline C24:0 ( Lignoceric acid ) & $1.41 \pm 0.02^{\mathrm{d}}$ & $1.45 \pm 0.02^{\mathrm{c}}$ & $1.87 \pm 0.02^{\mathrm{a}}$ & $1.58 \pm 0.02^{\mathrm{b}}$ \\
\hline$\sum$ Saturated (SFA) & 30.34 & 37.15 & 38.81 & 37.28 \\
\hline C14:1 ( Myristoleic acid ) & $0.12 \pm 0.02^{\mathrm{b}}$ & $0.14 \pm 0.01^{\mathrm{a}}$ & $0.12 \pm 0.02^{\mathrm{bb}}$ & $0.14 \pm 0.01^{\text {aa }}$ \\
\hline C15:1 (cis-10-pentadecenoic acid) & $0.07 \pm 0.01^{\mathrm{a}}$ & $0.06 \pm 0.02^{\mathrm{b}}$ & $0.06 \pm 0.02^{\mathrm{bb}}$ & $0.06 \pm 0.01^{\mathrm{bc}}$ \\
\hline C16:1 (Palitoleic acid) & $4.37 \pm 0.02^{\mathrm{d}}$ & $5.82 \pm 0.02^{\mathrm{c}}$ & $5.91 \pm 0.02^{\mathrm{b}}$ & $6.08 \pm 0.02^{\mathrm{a}}$ \\
\hline C17:1 (cis-10-Heptadecenoic acid) & $0.46 \pm 0.01^{\mathrm{a}}$ & $0.37 \pm 0.02^{\mathrm{c}}$ & $0.39 \pm 0.02^{\mathrm{b}}$ & $0.33 \pm 0.01^{\mathrm{d}}$ \\
\hline C20:1 (Paullinic acid ) & $2.15 \pm 0.02^{\mathrm{a}}$ & $2.11 \pm 0.02^{\mathrm{b}}$ & $1.91 \pm 0.02^{\mathrm{d}}$ & $2.07 \pm 0.01^{\mathrm{c}}$ \\
\hline C18:1n9 (Oleic acid) & $14.12 \pm 0.02^{\mathrm{d}}$ & $25.13 \pm 0.02^{\mathrm{c}}$ & $25.61 \pm 0.02^{\mathrm{a}}$ & $25.46 \pm 0.02^{\mathrm{b}}$ \\
\hline C22:1 (Erucic acid methyl) & $0.53 \pm 0.02^{\mathrm{d}}$ & $0.71 \pm 0.02^{\mathrm{a}}$ & $0.68 \pm 0.02^{\mathrm{b}}$ & $0.65 \pm 0.02^{\mathrm{c}}$ \\
\hline$\sum$ Monosaturated (MUFA) & 21.82 & 34.34 & 34.68 & 34.79 \\
\hline C18:2n6 (Linoleic acid) & $10.34 \pm 0.02^{\mathrm{b}}$ & $16.32 \pm 0.02^{\mathrm{c}}$ & $16.27 \pm 0.02^{\mathrm{d}}$ & $16.45 \pm 0.02^{\mathrm{a}}$ \\
\hline C18:3n6 ( y-Linoleic acid) & $0.19 \pm 0.02^{\mathrm{d}}$ & $0.21 \pm 0.02^{\mathrm{c}}$ & $0.24 \pm 0.01^{\mathrm{a}}$ & $0.22 \pm 0.01^{\mathrm{b}}$ \\
\hline C18:3n3 ( $\alpha$ - Linolenic acid) & $1.32 \pm 0.02^{\mathrm{c}}$ & $1.27 \pm 0.02^{\mathrm{d}}$ & $1.46 \pm 0.01^{\mathrm{a}}$ & $1.36 \pm 0.01^{\mathrm{b}}$ \\
\hline C20:2n6 (Eicosadienoic acid) & $0.75 \pm 0.02^{\mathrm{a}}$ & $0.59 \pm 0.02^{\mathrm{c}}$ & $0.57 \pm 0.01^{\mathrm{d}}$ & $0.63 \pm 0.01^{\mathrm{b}}$ \\
\hline C20:5n-3 (Ecosapentaenoic acid) & $3.67 \pm 0.01^{\mathrm{d}}$ & $4.26 \pm 0.02^{\mathrm{b}}$ & $4.16 \pm 0.02^{\mathrm{c}}$ & $4.33 \pm 0.02^{\mathrm{a}}$ \\
\hline C22:6n-3 (Docosahexaenoic acid) & $7.64 \pm 0.02^{\mathrm{d}}$ & $9.81 \pm 0.02^{\mathrm{c}}$ & $9.91 \pm 0.02^{\mathrm{b}}$ & $10.83 \pm 0.02^{\mathrm{a}}$ \\
\hline$\sum$ Polyunsaturated (PUFA) & 23.91 & 32.46 & 32.61 & 33.82 \\
\hline$\sum$ Usaturated & 45.73 & 66.80 & 67.29 & 68.61 \\
\hline SFA/MSFA & 1.39 & 1.08 & 1.12 & 1.07 \\
\hline SFA/PSFA & 1.27 & 1.15 & 1.90 & 1.10 \\
\hline SFA/USFA & 0.66 & 0.56 & 0.58 & 0.54 \\
\hline n $3 \sum$ & 12.63 & 15.34 & 15.53 & 16.52 \\
\hline$\sum$ n6 & 11.28 & 17.12 & 17.08 & 17.30 \\
\hline$\sum$ n3/n6 & 1.12 & 0.90 & 0.91 & 0.96 \\
\hline DHA/EPA & 2.08 & 2.30 & 2.38 & 2.50 \\
\hline
\end{tabular}




\subsection{Amino Acids Analysis}

The amino acid profiles of different culture media were presented for N.oceanica species. There was a clear discrepancy in the content of each individual amino acid between the different media. The results showed that $N$. oceanica recorded the highest percentage of EAA essential amino acids $(55.92 \%)$ by OB3 medium, while the lowest value was recorded by CO medium (100\% $\mathrm{F} / 2$ ). The results showed that the top four EAAs in OB3 medium were lysine $(5.81 \%)$ phenylalanine $(5.93 \%)$, histidine $(2.61 \%$ ) and isoleucine $(4.03 \%)$ (Table 4). And the opposite for non-essential amino acids (NEAA), where the highest percentage of NEAA (50.91\%) was detected by $\mathrm{CO}$ medium ( $100 \% \mathrm{~F} / 2)$, while the lowest value for NEAA was achieved by OB3 medium. . The three most abundant NEAAs in F/2 medium were aspartate $(10.13 \%)$, glutamine $(11.25 \%)$, serine $(6.31 \%)$ and proline.$(\% 6.31)$

Table 4. Amino acids profile (\%) in N. oceanica at different levels of Soaked Brown

Lentils (SBL) medium harvested after 10 days incubation period.

\begin{tabular}{|c|c|c|c|c|}
\hline \multirow[b]{2}{*}{ Amino acid (AA)\% } & \multicolumn{4}{|c|}{ Medium } \\
\hline & CO & OB1 & OB2 & OB3 \\
\hline & \multicolumn{4}{|c|}{ Essential amino acids $(E A A)$} \\
\hline Arginine & $5.52 \pm 0.02^{\mathrm{c}}$ & $5.91 \pm 0.02^{\mathrm{b}}$ & $5.94 \pm 0.02^{\mathrm{a}}$ & $5.41 \pm 0.02^{\mathrm{d}}$ \\
\hline Histidine (HIS) & $1.84 \pm 0.02^{\mathrm{d}}$ & $1.95 \pm 0.02^{\mathrm{c}}$ & $2.23 \pm 0.02^{\mathrm{b}}$ & $2.61 \pm 0.02^{\mathrm{a}}$ \\
\hline Isoleucine (ILE) & $3.74 \pm 0.02^{\mathrm{d}}$ & $3.83 \pm 0.02^{\mathrm{c}}$ & $3.91 \pm 0.02^{\mathrm{b}}$ & $4.03 \pm 0.02^{\mathrm{a}}$ \\
\hline Leucine (LEU) & $9.16 \pm 0.02^{\mathrm{d}}$ & $9.18 \pm 0.02^{\mathrm{c}}$ & $9.41 \pm 0.02^{\mathrm{b}}$ & $9.73 \pm 0.02^{\mathrm{a}}$ \\
\hline Lysine (LYS) & $4.33 \pm 0.02^{\mathrm{d}}$ & $4.52 \pm 0.02^{\mathrm{c}}$ & $4.71 \pm 0.02^{\mathrm{b}}$ & $5.81 \pm 0.01^{\mathrm{a}}$ \\
\hline Methionine (MET) & $4.42 \pm 0.01^{\mathrm{d}}$ & $4.63 \pm 0.02^{\mathrm{c}}$ & $4.67 \pm 0.02^{\mathrm{b}}$ & $4.83 \pm 0.02^{\mathrm{a}}$ \\
\hline Phenylalanine (PHE) & $6.51 \pm 0.02^{\mathrm{a}}$ & $5.03 \pm 0.02^{\mathrm{d}}$ & $5.87 \pm 0.02^{\mathrm{c}}$ & $5.93 \pm 0.02^{\mathrm{b}}$ \\
\hline Threonine (THR) & $5.64 \pm 0.02^{\mathrm{d}}$ & $5.89 \pm 0.02^{\mathrm{c}}$ & $6.47 \pm 0.02^{\mathrm{b}}$ & $6.91 \pm 0.02^{\mathrm{a}}$ \\
\hline Tryptophan (TRP) & $1.96 \pm 0.02^{\mathrm{d}}$ & $2.45 \pm 0.02^{\mathrm{c}}$ & $2.75 \pm 0.02^{\mathrm{a}}$ & $2.73 \pm 0.02^{\mathrm{b}}$ \\
\hline Valine (VAL) & $5.97 \pm 0.02^{\mathrm{d}}$ & $6.27 \pm 0.02^{\mathrm{c}}$ & $7.37 \pm 0.02^{\mathrm{b}}$ & $7.93 \pm 0.02^{\mathrm{a}}$ \\
\hline Total EAA & 49.09 & 49.66 & 53.33 & 55.92 \\
\hline \multicolumn{5}{|c|}{ Non-essential amino acids $(N E A A)$} \\
\hline Alanine (ALA) & $6.66 \pm 0.02^{\mathrm{d}}$ & $7.63 \pm 0.02^{\mathrm{c}}$ & $7.66 \pm 0.02^{\mathrm{b}}$ & $7.81 \pm 0.02^{\mathrm{a}}$ \\
\hline Aspartate (ASP) & $10.13 \pm 0.02^{\mathrm{a}}$ & $8.13 \pm 0.02^{\mathrm{b}}$ & $7.67 \pm 0.02^{c}$ & $6.14 \pm 0.02^{\mathrm{d}}$ \\
\hline Cystine (C-C) & $4.45 \pm 0.02^{\mathrm{b}}$ & $4.63 \pm 0.02^{\mathrm{a}}$ & $2.55 \pm 0.02^{\mathrm{d}}$ & $3.81 \pm 0.02^{\mathrm{c}}$ \\
\hline Glutamine (GLU) & $11.25 \pm 0.02^{\mathrm{b}}$ & $10.90 \pm 0.02^{\mathrm{c}}$ & $10.22 \pm 0.02^{\mathrm{d}}$ & $11.39 \pm 0.02^{\mathrm{a}}$ \\
\hline Glycine (GLY) & $4.35 \pm 0.02^{\mathrm{d}}$ & $4.51 \pm 0.02^{\mathrm{c}}$ & $5.66 \pm 0.02^{\mathrm{a}}$ & $4.71 \pm 0.02^{\mathrm{b}}$ \\
\hline Proline (PRO) & $5.25 \pm 0.02^{\mathrm{c}}$ & $5.64 \pm 0.01^{\mathrm{b}}$ & $6.43 \pm 0.02^{\mathrm{a}}$ & $5.21 \pm 0.02^{\mathrm{d}}$ \\
\hline Serine (SER) & $6.31 \pm 0.02^{\mathrm{b}}$ & $6.51 \pm 0.02^{\mathrm{a}}$ & $4.91 \pm 0.02^{\mathrm{c}}$ & $3.43 \pm 0.02^{\mathrm{d}}$ \\
\hline Tyrosine (TYR) & $2.51 \pm 0.02^{\mathrm{a}}$ & $2.39 \pm 0.02^{\mathrm{b}}$ & $1.57 \pm 0.02^{\mathrm{d}}$ & $1.58 \pm 0.02^{\mathrm{c}}$ \\
\hline Total NEAA & 50.91 & 50.34 & 46.67 & 44.08 \\
\hline
\end{tabular}




\section{Discussions}

Improving culture conditions is necessary to raise the efficiency and economic value of microalgae production in the future. New methods of efficient production and farming can be created to improve productivity and reduce costs. For more than 50 years, Guillard F/2 intermediate in marine aquaculture has been known for the cultivation of microalgae, currently, due to the various uses of microalgae in various fields of biotechnology; The F/2 Guillard broker has several drawbacks. Our results achieved that some levels of brown lentil soak achieved significant biochemical components compared to $\mathrm{F} / 2$ (control).

The present study showed that addition of medium (SBL) could improve the content of protein, carbohydrate, PUFA, EAA and biomass in N.oceanica algae. In protein it was higher than the results (Abugrara, et al., 2019), when used as a nitrogen source in the development of N.oceanica, due to the presence of urea, and closer to the results (Ashour, et al., 2019) who used (F/2 at 100\%) on the algae N.oceanica and higher than (Ashour M. and Abd El-Wahab K., 2017) when using 50-100\% nitrogen and phosphorous on the same algae.

As for fat, it was higher than the results of (Ashour et al., 2019 when using an average F/2, and higher than (Ashour M. and Abd El-Wahab K., 2017) when using 50-50\% nitrogen and phosphorous, and higher than ( Ashour M. and Abd El-Wahab K., 2017 (Zhang, et al., 2016) that used different levels of nitrogen, and was lower than what was achieved (Abugrara, et al., 2020) when using different levels of bicarbonate. Sodium in N. oculata was higher than (Ashour, et al., 2019) using an average F/2 on the same algae and lower than (Ashour M. and Abd El-Wahab K., 2017) when N-P was used at a ratio of 50-50. \% and less than (Chun W. et al., 2012) when using an average $\mathrm{F} / 2$ on the same algae.

Biomass productivity was higher than (Ashour, et al., 2019) using F/2 medium on the same algae, and higher than (Mata, et al., 2010) on N. oceanica alga.

The lipid yield was higher than the results (Ashour et al., 2019) when Medium F/2 was used on the same algae. The results were similar to (Aarón Millán et al., 2015) that used nitrate and $\mathrm{CO}_{2}$ on $N$. oculata and higher than the results (Chun Wan, et al., 2013) on the same alga using different nitrogen sources. This is what was found (Mata et al., 2010) in N.oculata.

It showed an increase in polyunsaturated fatty acids, and PUFA scored higher in OB3 than found (Abugrara, et al., 2020), where sodium bicarbonate was used on the same algae, and in DHA was also lower at all levels, and higher than (Ashour, et al., 2019). ), who used Medium F/2 on the same algae, and the results (Madhusree et al., 2016) were higher on the same algae where wastewater was used at different levels with some types of media, and were higher than the results of (Jean HB \& Sung Bum H ., 2011) when Medium F/2 was used on Nannochloropsis spp. , Nannochloropsis $s p$. As well as the highest proportion of essential amino acids, EAA at OB3 level was higher than (Abugrara, et al., 2020), NEAA was lower at this level, and it was higher than (Jean HB \& Sung Bum Hu., 2011). 


\section{Conclusion}

In summary, this research showed that it is possible to enhance the growth of biomass. The results indicated that the use of soaked brown lentils is a beneficial source of nitrogenous protein, and the use of $75-25 \%$ as a culture medium for N.oceanica had a significant impact on the production of chemical compounds. Including protein, carbohydrates, polyunsaturated fatty acids and essential amino acids (especially arginine and leucine) for their high nutritional value and essential for use in aquaculture feed.

\section{References}

Aarón, M. O., Luis, G. T. Bustillos., \& Luis, F. L. (2015). Simultaneous effect of nitrate $\left(\mathrm{NO}_{3}{ }^{-}\right)$ concentration, carbon dioxide $\left(\mathrm{CO}_{2}\right)$ supply and nitrogen limitation on biomass, lipids, carbohydrates and proteins accumulation in Nannochloropsis oculate. Biofuel Research Journal, 5, 215- 221.

Abomohra, A., Wagner, M., El-Sheekh, M., \& Hanelt, D. (2013). Lipid and total fatty acid productivity in photoautotrophic fresh water microalgae: Screening studies towards biodiesel production. Journal of Applied Phycology, 25, 931-936.

Abomohra, A. W., Jin, R., Tu, S., Han, M. E., \& Eladel, H. (2016). Microalgal biomass production as asustainable feedstock for biodiesel: current statusand perspectives, Renew. Sustain. Energy Rev., 64, 596-606.

Abugrara, A. M., El-Sayed, H. S., Zaki, M. A., \& Nour, A. M. (2019). Some Factors Affecting on Growth, Production of Marine Microalgae and Relation to Fish feeding. M.sc. Thesis, Faculty of Agriculture. El-Shatby, Alexandria University Department of animal and fish production.

Abugrara Ali, M. , Hanan, M. Khairy, Heba S. El-Sayed., \& Hoda H. Senousy. (2020). Effect of Various Bicarbonate Supplements on Biodiesel Production and Valuable Biochemical Components of the Marine Eustigmatophyceae Nannochloropsis oculata (Droop) Egypt. J. Bot. 60(3).

Ashour, M., \& Abd El-Wahab, K. (2017). Enhace growth and biochemical composition of Nannochloropsis oceanica, cultured under nutrient limitation, Using Commercial Agricultural Fertilizersm. J Marine Sci Res Dev, 7(4).

Ashour, M., MostafaE. Elshobary, Rania El-Shenody, Abdel-Wahab Kamil, \& AbdEl-FatahAbomohra. (2019). Evaluation of a native oleaginous marine microalga Nannochloropsis oceanica for dual use in biodiesel production and aquaculture feed. Biomass and Bioenergy, 120, 439-447.

Bajpai, R, Prokop, A, \& Mark, Z. (2014). Algal Biorefineries. Springer Science, Business Media Dordrecht. Library of Congress Control.

Becker, E. W. (1994). Microalgae Biotechnology and microbiology. Cambridge University Press, Cambridge. 
Block, R. J. (1948). Quantitative estimation of amino acids on paper chromatograms. Science, 108, 608609.

Bligh, E. G., \& Dyer, W. J. (1959). A rapid method for total lipid extraction and purification. Canadian Journal of Biochemistry and Physiology, 37, 911-917.

Cai, T., Park, S. Y., \& Li, Y. (2013). Nutrient recovery from wastewater streams by microalgae : status and prospects. Renew. Sustain. Energy Rev., 19, 360-369.

Carvalho, G. G. P.de, Pires, A. J. V., Garcia, R., Veloso, C. M., Silva, R. R., Mendes, F. B. L., Pinheiro, A. A., Souza, D. R.de. (2009). In situ degradability of dry matter, crude protein and fibrous fraction of concentrate and agro industrial by-products. Ciência Animal Brasileira, 10, 689-697.

Chun, W., Xin-Qing, Z. Suo-Lian, G., Md. Asraful, A., \& Feng-Wu, B. (2012). Bioflocculant production from Solibacillus silvestris W01 and its application in cost- effective harvest of marine microalga Nannochloropsis oceanica by flocculation. Bioresource Technology. http://dx.doi.org/10.1016/j.biortech.2012.10.004

Chun Wan, Feng-Wu Bai \& Xin-Qing Zhao. (2013). Effects of nitrogen concentration and media replacement on cell growth and lipid production of oleaginous marine microalga Nannochloropsis oceanica DUT01. Biochemical Engineering Journal, 78, 32- 38.

Dubois, M., Gilles, K. A., Hamilton, J. K., Rebers, P. A., \& Smith, F. (1956) Colorimetric method for determination of sugars and related substances. Analytical Chemistry, 28, 350-356.

Folch, J., Lees, M., \& GH, S.S. (1957). A simple method for the isolation and purification of total lipides from animal tissues. The Journal of Biological Chemistry, 226, 497-509.

Grobbelaar, J. U. (2010). Microalgal biomass production: Challenges and realities. Photosynthesis Research, 106, 135-144.

Guillard, R.L.L., \& Rhyter, J.H. (1962). Studies on marine planktonic diatoms I. Cyclotella nana Hustedt, Detonula confervacea (Cleve). Grans Can J Microbiol, 8, 229-239.

Hemaiswarya, S., Raja, R., Carvalho, I.S., Ravikumar, R., Zambare, V., \& Barh, D. (2011). An Indian scenario on renewable and sustainable energy sources with emphasis on algae. Applied Microbiology and Biotechnology, 96, 1125-1135.

Ho, S. H., Ye, X., Hasunuma, T., Chang, J. S., \& Kondo, A. (2014). Perspectives on engineering strategies for improving biofuel production from microalgae:a critical review. Biotechnol. Adv. 32, $1448-1459$.

Jean, H. B., \& Sung, B. H. (2011). Development of Economical Fertilizer-Based Media for Mass Culturing of Nannochloropsis oceanica. Fish Aquat Sci., 14(4), 317-322.

Lowry, O. H., Rosebrough, N. J., Farr, A. L., Randall, R. G. (1951). Protein measurement with folin phenol reagent. Journal of Biological Chemistry, 193, 265-275. 
Madhusree, M., Freny, S., Vamsi Bharadwaj, S.V., Shailesh, K. P., \& Sandhya, M. (2016). Cultivation of Nannochloropsis oceanica biomass rich in eicosapentaenoic acid utilizing wastewater as nutrient resource.

Mata Teresa, M., António, A. M., \& Nidia, S. C. (2010). Microalgae for biodiesel production and other applications. A review Renewable and Sustainable Energy Reviews, 14, 217-232.

Piggott, J. J., Salis, R. K., Lear, G., Townsend, C. R., \& Matthaei, C. D. (2015). Climate warming and agricultural stressors interact to determine stream periphyton community composition. Glob. Chang. Biol., 21, 206-222.

Radwan, S. S. (1978). Coupling of two- dimensional thin-layer chromatography with gas chromatography for the quantitative analysis of lipid classes and their constituent fatty acids. Journal of chromatographic science, 16(11), 538-542.

Sarker, P. K., Kapuscinski, A. R., Lanois, A. J., Livesey, E. D., Bernhard, K. P., \& Coley, M. L. (2016). Towards Sustainable Aquafeeds: Complete substitution of fish oil with marine microalga Schizochytrium sp. improves growth and fatty acid deposition in Juvenile Nile Tilapia (Oreochromis niloticus). PLOS One, 11, e0156684.

SPSS. (2007) Sigmastat Statistical Software (SPSS), Applied Statistics with SPSS. Templeton, D.W., Laurens. M.L. (2015). Nitrogen-toprotein conversion factors revisited for applications of microalgal biomass conversion to food, feed and fuel. Algal Research, 11, 359-367.

Tokuşoglu, O., \& Ünal, M. K. (2003). Biomass nutrient profiles of three microalgae: Spirulina platensis, Cholorella vulgaris, and Isochrisis galbana. Journal of Food Science, 68, 1144-1148.

Wang, Jinghan, Haizhen, Yang., \& Feng, Wang. (2013). Mixotrophic Cultivation of Scenedesmus sp. as Biodiesel Feedstock Advanced Materials Research, 777, 268-273 https://doi.org/10.4028/www.scientific.net/AMR.777.268

Zhang, Xuezhi, Zhiying, Lu, Yifei, Wang, Pierre, Wensel, Milton, Sommerfeld., \& Qiang, Hu, (2016). Recycling Nannochloropsis oceanica culture media and growth inhibitors characterization. Algae Research, 20, 282-290.

Zhu, Y., \& Dunford, N. T. (2013). Growth, Biomass Characteristics of Picochlorum oklahomensis, Nannochloropsis oculata. J Am Oil Chem Soc., 90, 841-849.

\section{Copyrights}

Copyright for this article is retained by the author(s), with first publication rights granted to the journal.

This is an open-access article distributed under the terms and conditions of the Creative Commons Attribution license (http://creativecommons.org/licenses/by/4.0/) 